International

Marketing

Review

15,3

162

\title{
Viewpoint: marketing in the information age - can we plan for an unpredictable future?
}

\author{
Bodo B. Schlegelmilch
}

Chair of International M arketing and M anagement, Vienna University of Economics and Business Administration, Vienna, Austria

\section{Rudolf Sinkovics}

A ssistant Professor in the Department of International M arketing and $M$ anagement, $V$ ienna University of E conomics and Business

Administration, Vienna, Austria

The nature of change has changed. It is not evolving in comfortable, incremental steps, but it is turbulent, erratic, and often rather uncomfortable. To illustrate the dramatic and paradigmatic nature of the changes brought about by information and communication technology (ICT), researchers resort to metaphors: parallels are drawn with the advent of electricity, the invention of the steam engine or even the invention of the wheel. Is everyone falling prey to hype? W hat is really changing and how does it affect the work marketers do, the topics we teach and the way we view our discipline? Deighton (1997) states that the "technological shock" will completely reshape the way marketing is done. B elow, we attempt the impossible. Placing the potential effects of ICT on the marketing discipline in the context of broader changes in the business environment, we venture to offer some implications for the future of our discipline - a future nobody can predict.

W hat then are some of the changes that have occurred so far? First, there is the explosive spread of the technology itself. It is estimated that the Internet, arguably the most important part of the new technological environment, has expanded by about 2,000 per cent in the last decade and that it is doubling in size every six to ten months (Hoffman and Novak, 1996). A nother revolution, voice recognition technology, is just round the corner. Rendering keyboards largely superfluous and thus finally fulfilling the science fiction notion of commanding a machine through the human voice, this technology will dramatically accelerate the use of computers and drive ICT into completely new applications (Business Week, 1998; Financial T imes, 1998). But not only the advances in computer technology are changing our environment beyond recognition. Looking at telephony, market liberalization has begun worldwide and is expected to bring down international rates by as much as 80 per cent over five years (T he E conomist, 1997a). A Iready, about two-thirds of the world's new telephone subscriptions are for mobile phones and in developed countries this share is as high as 75 per cent (T he E conomist, 1998b). 
The discontinuities addressed above will completely change the business environment as we know it. Below, we highlight five interrelated changes that are already occurring and subsequently explore how marketing has to adapt to prepare for an unpredictable future.

\section{Mushroom companies}

A well-known characteristic of mushrooms is, of course, that they grow virtually overnight but then often disappear rather quickly. Since the new ICT environment largely feeds on ideas and knowledge rather than being dependent on fixed assets, we coined this term to describe companies that seem to appear from now here to take advantage, and often lead, new business opportunities opened through technological advances. One example is Y ahoo Inc., which provides the largest search engine on the Internet. Only three years ago, Yahoo's co-founder, David Filo, was a relatively poor ex-student. Today, his online service leads the field in both traffic (65 million pages viewed per day) and advertising revenues. In 1997, Yahoo achieved sales of \$67.4 million and had 155 employees, Konr@d, 1998; http://www.pathfinder.com/money/hoovers/ corpdirectory/y/yahoo.html, 2 A pril, 1998). But while Internet search companies likeYahoo, Infoseek, Lycos, and Excite raised $\$ 170$ million by going public in 1996, Internet search facilities have become a commodity - there are now hundreds of ways to find and retrieve information on the Web. Net search business, where a few engines compete for a pool of willing advertisers, may soon take some casualties (http://www.pathfinder.com/money/moneydaily/ 1997/ 970116.moneyonline.html, 2 A pril, 1998) However, Yahoo might well survive. It has three times the market share of any of its competitors and has the advantage of being the first kid on the block.

A nother Web success story is A mazon, an online retailer of books that was only founded in 1995 and now offers some 2.5 million titles. A ccording to the company's Web site, its books have been bought by some 1.5 million people in 160 countries. How ever, here too the good days could be numbered. Barnes \& N obles, the number one bookseller in the US, has finally boosted its online presence and is attempting to take market share away from its Internet rival.

The final example is Netscape, which was founded in 1994 as Mosaic Communications. It offered the first version of its Internet Navigator one year later and, at its heydays in the first quarter of 1997, generated revenues in excess of $\$ 150$ million p.q. However, since October 1997, the company's stock has lost over half its value on fears that it will be the big loser in its browser war with Microsoft's Internet Explorer.

Given these dramatic business histories, it is not surprising that Microsoft's CEO Bill Gates - the richest A merican ever - supposedly said: "We are always two years away from failure" and Intel's CEO, A ndy Grove, coined the motto: "Only the paranoid survive" (Stopford, 1997). 
International

Marketing

Review

15,3

164

\section{Virtual enterprises}

Traditionally, division of labour follows two routes. Complex tasks are divided into subtasks and hierarchically coordinated within organisations. A Iternatively, multilateral competition between companies can be used. This is based on coordination through market mechanisms, such as bargaining, pricing and contracts. Recently, a third coordination mechanism has emerged: virtual enterprises - also referred to as interfirm networks. Conceptually located between the extremes of markets and organisational hierarchies, the legally independent companies in the new ork commit to carry out specified subtasks. However, in contrast to market arrangements, contracts are only incompletely specified and the duration of the cooperation tends to be open ended (Schober, 1997).

Virtual enterprises themselves can represent horizontal coordinations of companies in different businesses, for example the coordination of software developers and hardware manufacturers. A Iternatively, the term may refer to vertical coordination of companies in the same business along the value chain of a product or service. Electronic Data Exchange (EDI) facilities between a company and its suppliers represent an example of a virtual enterprise meeting this definition. A nother possible usage of the term, finally, would be the loose description of an office-less company. To facilitate the functioning of virtual enterprises, the use of enterprise-resource-planning (ERP) applications has become an important tool. The ERP market is booming accordingly. Last year, the four leading providers of ERP applications, namely SAP, with a market share of over 60 per cent, Oracle, Baan and PeopleSoft recorded a sales growth of 50 per cent (T he E conomist, 1998a).

\section{Electronic markets}

Utilising ICT to organise such virtual enterprise structures ultimately leads to "electronic markets," such as the SA BRE airline reservation system, which coordinates the tasks of travel agencies, airlines, hotels and car rental companies. Electronic markets differ in terms of the market transaction processes they support. While some may only offer search processes, others support bargaining, pricing, contract administration and control.

Currently, one of the main stumbling blocks for the use of electronic markets is still the payment through Internet. However, the development of efficient electronic payment systems is advancing rapidly. It is expected that by the year 2000, some 9 billion Internet transactions will involve so-called electronic cash (E-Cash) and by the year 2005, some 30 per cent of all consumer payments will be based on digital payment systems (Kristoferitsch, 1998).

\section{B lurring industry boundaries}

The answer to the proverbial question - what business are we in? - is getting increasingly complex. Chemical companies are heavily relying on electronics to manage production processes and large retailers have to be good at database 
management to administer the flow of their products. Of course, we are long used to the fact that car companies sell financial services (e.g. GM), petrol stations transformed themselves into supermarkets (e.g. BP) and software companies edge into the consulting business (e.g. SA P). Now, cable companies are offering access to the Internet through Web-T V and computer companies are selling gateway servers that make it easy to phone via the Net.

How information technology impacts the fabric of an industry can best be seen in drug research. Computer modelling techniques have reduced the requirement for "wet" chemistry in the design of new drugs. The application of computer technology to biological research, bioinformatics, is rapidly becoming a key component of pharmaceutical research (Financial T imes, 1998). In medicine, too, new technologies are blurring industry boundaries. The need to make diagnostic services available in remote locations - telemedicine - will require a redefinition of the skill-set of medical personnel.

\section{Fragvergence of cultural barriers}

The word "fragvergence" does not yet exist. We created it to refer to an apparent paradox, namely the simultaneous fragmentation and convergence of cultural boundaries. Fragmentation refers to the simultaneous presence of lifestyles that represent different cultural identities. Firat $(1997$, p. 79$)$ describes this phenomenon:

The consumer is ready to have Italian for lunch and Chinese for dinner, to wear Levi's 501 blue jeans for the outdoor party ... and try the Gucci suit at night to attend a Japanese exhibition.

Convergence, on the other hand, refers to the existence of identical products, consumption patterns and lifestyles across the globe. Nearly everywhere in the world one can drink a Coca-Cola, watch CNN, buy a Sony walkman or rent a Toyota. The oxymoronic coexistence of convergence and fragmentation has been made possible through the globalisation of information. Indeed, the globalisation of information has not only broken down country and cultural barriers, but contributed to the creation of new ones. Barriers which do not follow traditional ethnic or religious affiliations, but are based on sub-cultures such as "techies" versus "greens." A rguably, barriers within country boundaries will become more important than differences between counties.

\section{Implications for marketing management}

Mushroom companies, virtual enterprises, electronic markets, blurring industry boundaries and fragvergence of cultural differences all pose abundant challenges. The phenomena discussed are, of course, highly interrelated. We could, for example, cynically envisage a virtual mushroom enterprise which operates in an electronic market environment characterised by blurring industry boundaries. Below, we attempt to outline some of the implications for marketing management. 
International

Marketing

Review

15,3

166
M ushroom companies

M ushroom companies represent one of the most disturbing and difficult challenges to marketing managers, namely rapidly diminishing value of incumbency versus the increasing importance of speed and time-to-market. Seemingly strong market positions can erode overnight and new empires emerge with breathtaking speed. For marketers, an efficient and quick promotion of ideas, business concepts and services has become the key to success. To achieve this, the emphasis of communication policy has shifted from traditional media towards the Internet (A Ibers and Peters, 1997). B ut while the interactive nature of the Internet offers a wide array of communicative possibilities, such as the integration of text, video and sound, most marketers still need to acquire the necessary experience and knowledge to utilise all facets of the new medium.

In the race to be noticed, branding has also acquired a new dimension. A n important way to differentiate against competitors is to offer a unique ww waddress (a so-called "URL", i.e. unique resource locator) which is easy to remember and intimately resembles the company's name. A lthough it may be useful to provide certain "local" internet-pages according to the country of origin of the surfing individual, many commercial product vendors register with the ".com" rather than the local country domain (for example: ".uk" for Britain, ".de" for Germany or ".at" for A ustria), since this supposedly signals a stronger emphasis on global presence and provides a "global branding".

Virtual enterprises and electronic markets

These most clearly represent the transformation of the Internet from an entertainment/infotainment medium to a marketplace. To enable smooth running of such virtual enterprises, the use and optimal configuration of socalled enterprise-resource planning (ERP) applications is required. For marketing, which has traditionally focused on managing the relationships between a single company and its customers and - to a lesser extent - to its suppliers, this situation radically alters its role definition. The selection and, in particular the configuration of an appropriate ERP application has become an important strategic marketing task. No longer is ICT used to automate welldefined tasks within an organisation which can be left to ICT specialists and/or manufacturing people, but ICT is the framework and key instrument for designing and managing company external relationships. Consequently, the driving force for the success of virtual enterprises will be the ability of marketing managers to develop a sound understanding of the technological capabilities on offer and their ability to coordinate with ICT specialists in their own and other network companies. Moreover, marketers need to be able to transform the unique characteristics of the Inter net into tangible customer benefits.

The translation of specific Web capabilities into tailored customer benefits is connected to the use of the Internet as a marketing research instrument and the use of collected market research data in forming micro segments. A company 
offering CDs online, CD-NOW (http://www.cdnow.com/), demonstrates this principle. Following the collection of customer preference data at the initial e-mail subscription to their service, the company offers a "Top 10" CD list which is specifically tailored to the customer. Following an order, actual purchase data and expressed customer preferences are pooled to update the information held on the customer and to assemble even more specific and attractive offers for the given customer. A one-to-one segmentation has been achieved.

A mazon.com (http://www.amazon.com/) and other booksellers follow similar principles in making use of the Internet to create customer intimacy. Feedback corners on their Web-sites provide customers with the opportunity to comment on books or music charts. Chat rooms provide a forum to "meet" the author and discuss with people who have read the book. For marketing managers, it will be increasingly important to design Web-based measures, which foster the development of online communities and create customer loyalty.

The attribute "virtual" is particularly suitable for companies that can use the Internet for the physical distribution of their products. Software houses or companies that provide information services, such as stock-market information, weather reports, home banking, product test results, etc. fall into this category. Innovative products extending the range of information services sold on the Web appear nearly every day. One of the latest services is referred to as "firefly-technique." It helps companies to target consumer groups and provide special product offerings based on profiles of musical/reading preferences (http://www.firefly.com/). U sing preference data revealed by members of those communities can support promising micro marketing applications (Sivadas et al., 1998). For marketers working with such technologies, marketing is clearly not what it used to be. Warehouses get replaced by servers which distribute files and information, and traditional timeconsuming export marketing tasks like filling out custom forms are automated.

But even the marketing decisions in companies that need to ship their products through traditional distribution channels will be profoundly affected by advances in ICT. Superb software will make it easier than ever to outsource the transportation and warehouse function to logistic experts. A pplying this approach in a retail environment will give rise to virtual enterprises which act as exchange agents for data and information that link producers and consumers. Their main function will be to coordinate date, time and conditions of delivery. For marketing managers, these forms of virtual enterprises necessitate a fundamental shift in orientation towards the marketing of information. At the same time, the possibility of organising a business around some sophisticated piece of software lowers market entry barriers and is already enabling small companies to compete in traditional retail environments. A gain, marketing of such new competitors is characterised by their ability to excel in the design of meaningful consumer interactions via the $\mathrm{N}$ et. A $\mathrm{n}$ example of such a company is Virtual Vineyards (http://www.virtualvin.com), which offers wine online. It remains to be seen whether established retailers can 
International Marketing Review 15,3

168 reclaim market share in the online community once they have properly set up their Web-stores.

Blurring of industry boundaries will go hand in hand with increased uncertainty. The implications for marketing managers will be twofold. First, marketing managers will need to develop their ability to gain a quick but firm grounding in the scope offered by new and unfamiliar technologies. Second, in an attempt to reduce uncertainty, marketing managers will have to find new avenues to support their strategic decision making. To this end, the application of sophisticated modelling techniques to forecast consumer acceptance of emerging business concepts and the use of the Web for product testing and development is likely to increase.

A number of reasons suggest that market research on the Internet is likely to increase in importance (Pitkow and Recker, 1994). The problem that current users of the Web are unrepresentative of the population as a whole (more males, higher incomegroups, higher education achievements) will soon diminish. With every new user getting online, the Internet will become more representative. Indeed, the current user biases might soon be overcome by introducing Webtechnology to the TV or by developments like NetPC or Web-enabled consumer consoles. Moreover, data collection via the Internet is fast and, consequently, lends itself to applications in marketing situations where speed is of the essence and uncertainties need to be resolved quickly. As such, the Internet provides promising potential for focus group research, consumer-panels and product chat-rooms. Kodak, for instance, uses online focus groups and chat-rooms to enhance product and service quality and to explore the acceptance of new product concepts (see the photochat section at: http://www.kodak.com/). Through this approach, Kodak uses consumer responses gathered on the Web to reduce the uncertainties involved in the introduction of unfamiliar technologies.

F ragvergence of cultural differences

Finally, fragvergence of cultural differences will have profound implications for the definition of international marketing. When target groups are routinely scattered throughout different countries around the globe, the majority of all marketing activities will have to be international. Marketing managers, therefore, need to develop a deep understanding of the idiosyncrasies of global marketing. How ever, companies can no longer rely on geographical markets to be dominated by a singular culture (e.g. the Spanish culture). Ethnically based cultural differences (e.g. food consumption habits) are widely experienced outside their original context and culture itself is becoming a commodity represented through its tradeable artefacts. Thus, marketing managers will need to revisit the meaning of cultural differences in an environment where information is global and cultural and social proximity - feelings of "closeness" and "familiarity" - are created through media. 
When social proximity is largely created through interactive media and not through personal contacts, personal sales activities will no longer be personal at all. Textbook marketing distinctions become blurred.

In today's world, if you want to reach 12 people, that's easy: you use the phone. If you want to reach 12 million people, it's easy: you take out an ad during the Superbowl. But if you want to pitch something to 10,000 people- the hard middle - that's really hard. (A mazon's CE O, Bezos in The E conomist, 1997b, p. 17)

The Internet helps to target and communicate with potentially interested consumers. Specialized search services like InfoSeek or Lycos sell keywords for "airline tickets" and can ensure that advertising banners for specialised travel agencies pop up on the search result list.

The capabilities of the Internet provide new opportunities to achieve a virtual one-to-one relationship for enhancing customer intimacy. However, for global companies, the properties of the Internet may also limit their marketing scope. W hile pricing used to be the least standardised marketing mix element in global marketing, the advent of the Internet will reduce the ability for price discrimination across countries and, thus, reduce revenues (Peterson et al., 1997). The emergence of intelligent agents which are able to automatically research the best price for a distinct product will help to reduce consumers' search costs (see A ndersen Consulting's Smart Store $(R)$ V irtual initiative HY PERLINK http://bf.cstar.ac.com/bf/ http://bf.cstar.ac.com/bf/). Based on such technological advances, price transparency will increase and reduce the willingness of consumers to accept price differences.

\section{Summary}

The examples discussed above illustrate that ICT is completely reshaping the way we communicate with others, conduct our business, target customers or distribute products and services. Indeed, the changes we are currently witnessing are so far reaching that the advancements in ICT are nothing short of a "technological shock" (Gatlin et al., 1997).

The eminent business writer Handy (1989) already pointed out that discontinuous change requires discontinuous thinking. For marketing managers, this implies that the new ICT environment will favour those who are willing to "think out of the box." Managers who will use the technology to find new ways of conducting business, managers who will redefine the bases for competition in an industry, and managers who will successfully appeal to the imagination of customers located in different parts of the globe but are united by a common interest or lifestyle will be the successful ones. In short, for marketing to survive and prosper in the information age marketing managers need to break with established rules. Planning for business as usual, in contrast, would be a recipe for failure.

\section{References}

A lbers, S. and Peters, K. (1997), "Die Wertschöpfungskette des Handels im Zeitalter des Electronic Commerce", M arketing ZF P, Heft 2, 2. Quartal, pp. 69-79. 
International Marketing

Review 15,3
Business Week (1998), "Special report. Let's talk", February 23, pp. 44-56.

Deighton, J. (1997), "Commentary on exploring the implications of the Internet for consumer marketing", J ournal of the A cademy of M arketing Science, Vol. 25 No. 4, pp. 347-51.

E conomist (T he) (1997a), "A survey of telecommunications: a connected world", September 13, pp. 1-42.

E conomist (T he) (1997b), “Electronic commerce survey”, May 10, pp. 1-26.

E conomist (T he) (1998a), "Oracle. M ore than vision”, March 7, p. 86-7.

E conomist (T he) (1998b), "E conomic indicators", M arch 28, p. 112.

Financial T imes (1998), "Smitten with the written word", February 12, p. 21.

Firat, F.A. (1997), "Globalization of fragmentation - a framework for understanding contemporary global markets", Journal of International M arketing, Vol. 5 No. 2, pp. 77-86.

Gatlin, R., A rn, J. and Kordsmeier, W. (1997), "Innovative multimedia instructional approaches as perceived by AACSB deans", Proceedings of the Western Region Decision Sciences Institute A nnual M eeting, Kailua-Kona, Hawaii, March, pp. 341-5.

Handy, C. (1989), T he A ge of Unreason, Harvard Business School Press, Boston, M A, p. 23.

Hoffman, D.L. and Novak, T.P. (1996). "A new marketing paradigm for electronic commerce", Project 2000 working paper, Owen Graduate School of Management, Vanderbilt University, Nashville, T N. [URL .http.//www2000.ogsm.vanderbilt.edu/novak/ new.marketing. paradigm. html].

Konr@d (1998), “M onitor. Blick in die digitale Welt.” January, p. 11.

Kristoferitsch, G. (1998), Digital M oney - Electronic Cash - Smart Cards. Chancer and Risiken des Zahlungsverkehrs via Internet, U eberreuter, W ien.

Peterson, R.A ., Balasubramanian, S. and B ronnenberg, B.J. (1997), "Exploring the implications of the Internet for consumer marketing", Journal of the A cademy of M arketing Science, Vol. 25 No. 4, pp. 329-46.

Pitkow, J.E. and Recker, M.M. (1994), "Using the Web as a survey tool. Results from the second WW W user survey" [URL. http.//www.cc.gatech.edu/gvu/ user_surveys/survey-09-1994].

Schober, F. (1997). "Information technology and organizational change - how stable is the virtual enterprise?" A rbeitsbericht des Lehrstuhls für W irtschaftsinformatik, A Ibert-LudwigsUniversität, Freiburg i. Br.

Sivadas, E., Grewel, R. and Kellaris, J. (1998). "T he Internet as a micro marketing tool. Targeting consumers through preferences revealed in music newsgroup usage", Journal of Business Research, Vol. 41 No. 3 (M arch), pp. 179-86.

Stopford, J. (1997), "Global strategies for the information age", Keynote speech at the 23rd Eiba Conference, Stuttgart, Germany, December 14-16. 